\title{
M. A. Dumas, Prologue de ma vie
}

\section{Lise Sabourin}

\section{OpenEdition}

\section{Journals}

\section{Édition électronique}

URL : http://journals.openedition.org/studifrancesi/10677

DOI : 10.4000/studifrancesi. 10677

ISSN : 2427-5856

\section{Éditeur}

Rosenberg \& Sellier

\section{Édition imprimée}

Date de publication : 1 décembre 2017

Pagination : $566-567$

ISSN : 0039-2944

\section{Référence électronique}

Lise Sabourin, « M. A. Dumas, Prologue de ma vie », Studi Francesi [En ligne], 183 (LXI | III) | 2017, mis en ligne le 01 février 2018, consulté le 24 janvier 2021. URL : http://journals.openedition.org/ studifrancesi/10677 ; DOI : https://doi.org/10.4000/studifrancesi.10677

\section{Ce document a été généré automatiquement le 24 janvier 2021.}

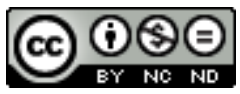

Studi Francesi è distribuita con Licenza Creative Commons Attribuzione - Non commerciale - Non opere derivate 4.0 Internazionale. 


\title{
M. A. Dumas, Prologue de ma vie
}

\author{
Lise Sabourin
}

\section{RÉFÉRENCE}

MARIE ALEXANDRE DUMAS, Prologue de ma vie, suivi des lettres de Dumas à sa fille, Paris, Classiques Garnier, 2013, «Cahiers Alexandre Dumas» 40, 259 pp.

1 Ce $40^{\circ}$ numéro des "Cahiers Alexandre Dumas», avec son habituelle bibliographie annuelle, est consacré à la «fille d'Antony, et sœur de la Dame aux camélias» comme disait Francis Magnard, que cite l'introduction évoquant celle qui revendiqua pour second prénom celui du grand romancier (pp.11-16). Si elle lui ressemblait physiquement, elle vécut dans un mysticisme qui n'avait rien à voir avec la joyeuse vie de son père; pourtant l'affection était réciproque comme en témoignent les documents ici réunis.

2 Claude schopp propose en $1^{\text {re }}$ partie la transcription de Prologue de ma vie (pp. 21-67) de Marie Dumas, effectuée d'après une copie autographe conservée à Auckland Library, avec répertoire biographique et index des lieux cités. Ce récit autobiographique de 1858 , resté inédit jusqu'à présent, révèle les comptes à régler de l'adolescente envers Ida Ferrier, «sa très chère et bonne petite mère», qui lui apparaissait en réalité comme une marâtre, alors qu'elle se voulait «élève de Mlle Félicie de Fauveau», la sculptrice qui, en lui apprenant le dessin, lui ouvrait la voie de sa libération.

3 La $2^{\mathrm{e}}$ partie fournit une chronologie de sa vie (1831-1878), établie par Christian MOREAU (pp. 71-126), qui montre bien ses relations avec son père, son frère et son triste époux, en même temps que son désir d'exister par elle-même en tant qu'artiste.

4 Ensuite viennent en $3^{\text {e }}$ partie, intitulée «Marie Alexandre Dumas écrivain» (pp. 127-153), deux études sur ses romans, Au lit de mort, due à Angels SANTA et Carmen Figuerola (pp.129-144), Mme Benoit et Le Mari de Mme Benoît, par Julie ANSELMINI (pp. 145-154). Marie se démultiplie dans ses personnages, recourant au roman épistolaire mais aussi au fantastique, pour transfigurer son expérience de la passion fatale et ses voyages en Europe centrale et en Orient. 
5 Suit en $4^{\mathrm{e}}$ partie «Le doux nom de Marie» (pp. 155-165) une anthologie de poèmes de son mari, Olinde Petel, entre déclaration d'amour et désenchantement spleenétique.

6 Enfin la $5^{\mathrm{e}}$ partie présente les lettres d'Alexandre Dumas à sa fille, de 1852 à 1869 (pp. 167-256). Comme souvent dans celles à son fils, les détails financiers y abondent, mais aussi les informations sur l'avancée de ses activités en un dialogue familier témoignant de leur tendresse. 